\title{
Mikołaj z Tuchowa \\ Zapomniany astronom i lekarz z XV wieku oraz jego europejskie peregrynacje
}

\begin{abstract}
Zarys treści: Artykuł poświęcony jest omówieniu działalności Mikołaja z Tuchowa, zapomnianego astronoma i lekarza z XV w., który zrobił karierę w Europie Zachodniej. Po studiach w Krakowie i Paryżu zajmował wpierw katedrę astronomii w Salamance, a potem był astronomem na dworze książąt burgundzkich (1464-1472) i lekarzem (od 1476) na dworze królów kastylijskich.
\end{abstract}

Abstract: The paper is devoted to the activities of Mikołaj of Tuchów, a forgotten astronomer and physician of the $15^{\text {th }}$ century, who made a career in Western Europe. After university studies in Cracow and Paris, he took over the chair of astronomy in Salamanca, and afterwards was an astronomer at the court of Dukes of Burgundy (1464-1472) and a physician (from 1476) at the court of Kings of Castile.

Słowa kluczowe: Astronomia na Półwyspie Iberyjskim w XV w., Mikołaj z Tuchowa, medycyna w Królestwie Kastylii w XV w., średniowieczne tablice astronomiczne, dwór burgundzki w drugiej połowie XV w.

Keywords: astronomy on the Iberian Peninsula in the 15th century, Mikołaj of Tuchów, medicien in the Kingdom of Castile in the 15th century, medieval astronomical tables, the court of Burgundy in the second half of the $15^{\text {th }}$ century

W średniowiecznych księgach uniwersytetu w Salamance, zwanych libros de claustros, zapisano 22 III 1464 r. informację, że wicerektor uniwersytetu Diego de Castro powierzył katedrę astronomii Juanowi de Salaya z powodu recessum et longam absenciam venerabilis viri Nicholai Polonii eiusdem cathedre ultimi cathedratici $^{1}$. Kim był tajemniczy Mikołaj Polak, który w połowie XV stulecia kierował katedrą astronomii w dalekiej Salamance na Półwyspie Iberyjskim i który tę katedrę gdzieś przed 1464 r. opuścił w nieznanych bliżej okolicznościach? W identyfikacji tegoż Mikołaja kluczowe okazało się połączenie go z Mikołajem z Tuchowa z diecezji

${ }^{1} \mathrm{~J} . \mathrm{C}$ h a b á s, Astronomy in Salamanca in the mid-fifteenth century: the tabulae resolutae, Journal for the History of Astronomy 29, 1998, s. 172; t e n ż e, The University of Salamanca and the Renaissance of Astronomy during the second half of the 15th Century, w: Universities and Science in the Early Modern Period, Dordrecht 2006, s. 30. Regest w języku hiszpańskim: Extractos de los libros de claustros de la Universidad de Salamanca, siglo XV (1464-1481), wyd. F.M. Rodríguez, Salamanca 1964, s. 51, nr 2. 
krakowskiej, który studiował w Krakowie i Paryżu. W 1447 r. wpisał się do metryki Uniwersytetu Krakowskiego jako Nicolaus Nicolai de Thuchow ${ }^{2}$. W zapisie imienia ojca nastąpiła zapewne pomyłka uniwersyteckiego skryby, który dane immatrykulacyjne wpisywał do Metryki nie na bieżąco, lecz partiami co jakiś czas - ojcem Mikołaja był bowiem zapewne Fabian, o czym świadczy nota w kolofonie traktatu medycznego zachowanego w rękopisie Biblioteki Jagiellońskiej (nr 839). Mikołaj z Tuchowa był kopistą dużej części tego rękopisu (k. 1r-47v i 92r-218v), w którym mieści się 15 traktatów i drobnych tekstów medycznych. W kolofonie traktatu Jana Serapiona Liber de simplicibus medicinis aggregacionum Serapionis, znanego powszechnie pod tytułem Liber aggregatus Serapionis in medicinis simplicibus, Mikołaj określił się jako: magister Nicolaus Polonus, filius Fabiani, philosophus Parisiensis, in medicina licenciatus $^{3}$. Podane informacje jednoznacznie identyfikują Mikołaja syna Fabiana z Mikołajem z Tuchowa, który w 1456 r. uzyskał w Paryżu stopień bakałarza sztuk wyzwolonych (Nicolaus Polonus de Thuchovia diocesis Cracoviensis $^{4}$ ). Rok wcześniej tenże Mikołaj z Tuchowa opracował tablice astronomiczne dla Krakowa, bawiąc wówczas $\mathrm{w}$ polskiej stolicy5. Samą pracę zaś napisał zapewne w gościnie u braci dominikanów, jak wynika z jego noty zamieszczonej w zachowanym w Bibliotece Narodowej w Paryżu rękopisie astronomicznym (Lat. 7427) ${ }^{6}$. Pobyt Mikołaja w dominikańskim klasztorze stanowi znakomite potwierdzenie związków łączących uniwersytet z tym zakonem po dokonanej w $1450 \mathrm{r}$. inkorporacji zakonnego studium generalnego do Uniwersytetu Krakowskiego 7 .

Krakowskie studia Mikołaja nie są co prawda potwierdzone uzyskaniem stopnia naukowego z zakresu sztuk wyzwolonych, niemniej sam Mikołaj posiadał sporą wiedzę z gramatyki, retoryki i poetyki, którą wyniósł ze swoich krakowskich stu-

${ }^{2}$ Metryka Uniwersytetu Krakowskiego z lat 1400-1508, wyd. A. Gąsiorowski, T. Jurek, I. Skierska, przy współpracy R. Grzesika, Kraków 2004, t. I, s. 215, nr 47e/040.

${ }^{3}$ Catalogus codicum manuscriptorum medii aevi latinorum qui in Bibliotheca Jagellonica Cracoviae asservantur, t. VI, Cracoviae 1996, s. 350-351. Wydawcy tego tomu próbują identyfikować Mikołaja jako syna Fabiana z Buku, który wpisał się na Uniwersytet w $1418 \mathrm{r}$. (Metryka, t. I, s. 96, nr 18/052), co jest błędne. Identyfikację tę powtórzyli też autorzy bazy studentów Uniwersytetu Krakowskiego (Corpus academicorum Cracoviense): $<$ https://cac. historia.uj.edu.pl>. Bez identyfikacji odnotowuje ten traktat również G. R o s i ń s k a, Scientific writings and astronomical tables in Cracow. A census of manuscript sources (XIVth-XVIth centuries), Wrocław 1984 (Studia Copernicana 22), s. 312.

${ }^{4}$ Auctarium chartularii Universitatis Parisiensis, t. II, wyd. H. Denifle, A. Chatelain, Parisiis 1897, kol. 911. Poprawnej identyfikacji Mikołaja, na podstawie źródeł paryskich, dokonali wydawcy krakowskiej Metryki, t. II, s. 519, przyp. 1054.

5 J. P. B o u d e t, Lire dans le ciel. La bibliothèque de Simon de Phares, astrologue du XVe siècle, Bruxelles 1994, s. 101: Per eundem Nicolaum studentem protunc Cracoviensem facta hoc est.

${ }^{6}$ Bibliothèque nationale de France, Lat. 7427, k. 43-55, nota na k. 43r: He tabule sunt almanach motuum planetarum anni ere Incarnationis Christi 1455 ad latitudinem civitatis inclite Cracovie calculate per Nicolaum de Thuchovia in benedicto ac mihi multum complacito monasterio Sancte Trinitatis. Rękopis dostępny online: <https://gallica.bnf.fr/ark:/12148/ btv1b100370843>. Jego zawartość omawia szczegółowo J.P. B o u d e t, Lire dans le ciel, s. $99 \mathrm{n}$.

${ }^{7}$ M. Z d a n e k, Szkoły i studia dominikanów krakowskich w średniowieczu, Warszawa 2005, s. 140 n. 
diów, a której dowodzi zawarty we wspomnianym rękopisie paryskim wiersz jego autorstwa, zaczynający się od słów: Nescio quid pueri mihi nuper frivola cornix ${ }^{8}$. Studia kontynuował Mikołaj na Uniwersytecie Paryskim, gdzie uzyskał wspomniany stopień bakałarza (1456), a następnie licencjata (1457) oraz magistra (1458), a także bakałarza medycyny $(1457)^{9}$.

Niewiele można powiedzieć o rodzinie i środowisku pochodzenia Mikołaja. Tuchów należał do benedyktynów z Tyńca, prawdopodobnie już od chwili fundacji klasztoru. W 1340 r. benedyktyni otrzymali królewskie zezwolenie na lokację miasta na prawie magdeburskim na obszarze 60 łanów przy wsi. Władca obdarował miasto targami tygodniowymi we wtorki, zaś w 1463 r. Tuchów otrzymał przywilej na dwa jarmarki (na Narodzenie NMPanny i św. Jakuba, co odpowiadało odpustom w starym i nowym kościele parafialnym $)^{10}$. Pomimo tych przywilejów Tuchów był miasteczkiem niedużym, w XVI w. liczba jego mieszkańców nie przekraczała 500 ${ }^{11}$. W 1456 r. parafia tuchowska została inkorporowana do klasztoru tynieckiego, zaś pięć lat później utworzono z niej prepozyturę klasztorną ${ }^{12}$. Widać zatem, że Mikołaj pochodził z małego miasteczka. Zapewne miejsce swojego pochodzenia i materialne problemy w młodości miał na myśli, pisząc po polsku na marginesie wspomnianego wyżej rękopisu paryskiego: „Stluczone vbostwo”"13. Studia w Krakowie, a potem w Paryżu pozwoliły mu bowiem pokonać ubóstwo i otworzyły drogę do kariery i pieniędzy.

Mikołaj z Tuchowa w literaturze polskiej jest znany jedynie z krótkich not słownikowych jako kopista dużych fragmentów wspomnianego rękopisu medycznego (Biblioteka Jagiellońska, ms. 839) ${ }^{14}$. Zupełnie nieznana jest natomiast jego działalność jako astronoma i lekarza w krajach Europy Zachodniej. Duże zainteresowanie nim okazywali natomiast badacze średniowiecznych dziejów uniwersytetu

8 J. P. B o u d e t, Lire dans le ciel, s. 101.

9 Auctarium chartularii Universitatis Parisiensis, t. II, kol. 916, 918, t. VI, wyd. A. L. Gabriel, G. C. Boyce, Parisiis 1964, kol. 274-275, 295, 300; E. W i c k e r s h e i m e r, Commentaires la Faculté de médecine de l'Université de Paris (1395-1516), Paris 1915, s. 213.

${ }^{10}$ F. K i r y k, Miasta regionu tarnowskiego - Tarnów, Tuchów, Ciężkowice do końca XVI w., w: Tarnów. Dzieje miasta i regionu, red. F. Kiryk, Z. Ruta, Tarnów 1981, s. 279 n.; t e n ż e, Urbanizacja Małopolski. Województwo sandomierskie XIII-XVI wiek, Kielce 1994, s. 153; F. K rog u ls k i, Miasto Tuchów do roku 1657, Tuchów 2016 (Materiały do dziejów Tuchowa 7), s. 28, 32.

${ }^{11}$ F. K i r y k, Urbanizacja, s. 153.

12 Z. Galo c h, Prepozytura benedyktyńska w Tuchowie 1460-1821, Kraków 2004; T.M. Gr o n o w s ki, Zwyczajny klasztor, zwyczajni mnisi. Wspólnota tyniecka w średniowieczu, Kraków 2007, s. 287.

${ }_{13}$ Bibliothèque nationale de France, Lat. 7427, k. 41r <https://gallica.bnf.fr/ark:/12148/ btv1b100370843/f45.item>; zob. Słownik staropolski, t. VIII, Wrocław 1981, s. 443-444. Za zwrócenie uwagi na tę polską glosę serdecznie dziękuję uważnemu recenzentowi wewnętrznemu mego artykułu.

14 J. R o stafiński, Medycyna na Uniwersytecie Jagiellońskim w XV wieku, Kraków 1900, s. 84; F. G i e d r o y ć, Źródła biograficzno-bibliograficzne do dziejów medycyny w dawnej Polsce, Warszawa 1911, s. 834; A. B e d n a r s k i, Materiały do dziejów medycyny polskiej w XIV i XV stuleciu, Kraków 1938, s. 26; A. G i e y s z t o r, Mistrzowie polscy Uniwersytetu Paryskiego w XIV i XV wieku, w: Wieki średnie. Medium aevum. Prace ofiarowane Tadeuszowi Manteufflowi w 60. rocznicę urodzin, Warszawa 1962, s. 224. 
w Salamance oraz astronomii na Półwyspie Iberyjskim ${ }^{15}$. Mniej znana jest natomiast jego aktywność jako astronoma na dworze książąt Burgundii, a potem jako lekarza królów kastylijskich.

Mikołaj po zakończeniu nauki w murach paryskiej Sorbony udał się zapewne do Salamanki, gdzie objął nowo powstałą katedrę astronomii. Podczas tamtejszego pobytu opracował kilka dzieł astronomicznych, które zachowały się w rękopisie Canonici Misc. 27 Biblioteki Bodleiana w Oxfordzie. Na kartach 33-88 znajdują się tablice astronomiczne (tzw. tabulae resolutae) poświęcone Salamance, zatytułowane Tabulae ad meridianum Salamantinum, natomiast na kartach $122 \mathrm{v}-129$ jest zamieszczony tekst w 18 rozdziałach (zwanych kanonami), który miał służyć studentom w Salamance do objaśniania położenia Słońca i Księżyca oraz znanych wówczas planet ${ }^{16}$. Mimo że wspomniane utwory nie są podpisane, ich autorstwo przypisuje się Mikołajowi. Dowodzi tego przede wszystkim dzieło innego profesora astronomii na uniwersytecie w Salamance, Diego de Torresa, który w swym Opus astrologicum (1487) trzykrotnie wspomina Mikołaja Polaka jako autora tablic astronomicznych dla Salamanki. Autorstwo Mikołaja potwierdza też Antonio de Nebrija w swoim napisanym w Salamance ok. 1495 r. słowniku hiszpańsko-łacińskim (Diccionario Hispano-Latino). Nebrija spędził w Salamance lata 1455-1460, przed udaniem się na całą dekadę do Bolonii. Jeśli wspomina w swoim słowniku wybitnego matematyka z Polski, to znaczy, że ten musiał pojawić się w Salamance najpóźniej w 1460 r., a zapewne nieco wcześniej, skoro dał się poznać jako znawca astronomii ${ }^{17}$. Badacze hiszpańscy, opierając się na artykule Jerzego Dobrzyckiego, zwracają uwagę, że opracowane przez Mikołaja dla Salamanki kanony zostały oparte na tablicach sporządzonych w 1448 r. przez Andrzeja Grzymałę z Poznania dla studentów Uniwersytetu Krakowskiego ${ }^{18}$. Jest to bardzo możliwe, skoro nasz Mikołaj, jak już wspomniałem, zapisał się na krakowską wszechnicę w 1447 r. i zapewne słuchał wykładów Andrzeja Grzymały, który ok. 1449-1450 r. przeszedł z katedry astronomii na katedrę poetyki i retoryki ${ }^{19}$.

${ }^{15}$ G. B e a uj o u a n, L'astronomie dans la Péninsule Ibérique a la fin du Moyen Âge, Revista da Universidade de Coimbra 24, 1971, s. 22-24; A. G a r c í a Avi l é s, Arte y astrología en Salamanca a finales del Siglo XV, Anuario del Departamento de Historia y Teoría del Arte 6, 1994, s. 40-41; J. Ch a bá s, Astronomy, s. 172-173; te nże, The University, s. 30-32; B. Porres de Mateo, J. Chabás, Los cánones de las Tabulae Resolutae para Salamanca origen y transmisión, Cronos 1, 1998, s. 51-83. Mikołaj z Tuchowa ma też swój biogram: E. W i c k er s h e i m er, Dictionnaire biographique des médecins en France au Moyen Âge, Paris 1936, s. 578, gdzie jednak błędne przypisano mu autorstwo rękopisu Stellarum fata anni 1477 (obecnie przechowywanego w Monachium), którego autorem był w rzeczywistości inny znany astronom i lekarz XV w., Mikołaj Wódka z Kwidzynia (o nim zob. L. A. B i r k e n m a j e r, Mikołaj Wodka z Kwidzynia zwany Abstemius, lekarz i astronom polski XV-go stulecia, Roczniki Towarzystwa Naukowego w Toruniu 33, 1926, s. 110 n.).

${ }_{16}$ J. C h a bá s, Astronomy, s. 172-173; te n że, The University, s. 30-31.

17 J. Ch a bá s, The University, s. 30-31.

18 J. Dobrzycki, The 'Tabulae Resolutae', w: De astronomia Alphonsi regis, wyd. M. Comes, R. Puig, J. Samsó, Barcelona 1987, s. 71-77; przedruk w: J. Dobrzycki, Selected Papers on Medieval and Renaissance Astronomy, Warsaw 2010, s. 129-135. Zob. J. C h a b á s, Astronomy, s. 172; te n ż e, The University, s. 31.

19 A. B irke n m a j er, Andrzej Grzymała z Poznania, astronom i lekarz z XV wieku, Kwartalnik Historii Nauki i Techniki 3, 1958, nr 3, s. 412. Mikołaj utrzymywał przez pewien 
Po opuszczeniu Salamanki Mikołaj udał się na dwór księcia Bretanii Franciszka II w Nantes, gdzie jest potwierdzony jako nadworny astrolog w listopadzie $1462 \mathrm{r}^{20}$ Nie zagrzał tam jednak długo miejsca, bo dwa lata później pojawia się jako astronom na dworze książąt Burgundii. Jego angaż w służbie książąt Filipa III Dobrego i Karola I Zuchwałego jest potwierdzony źródłowo latach 1464-1472². W archiwum w Lille zachowały się szczegółowe wykazy wypłacanego Mikołajowi uposażenia, jak również wystawiane przez niego kwitancje ${ }^{22}$. Te ostatnie mają standardowy charakter. Mikołaj potwierdza w nich, że otrzymał od książęcego skarbnika pewną sumę pieniędzy z tytułu pełnienia funkcji książęcego astronoma. Kwitancje Mikołaj takie sporządzał co kilka miesięcy ${ }^{23}$. Z zachowanych wykazów wynika, że roczne uposażenie Mikołaja wynosiło 50 funtów flandryjskich i początkowo było wypłacane kwartalnie po 12 funtów i 10 sous (20 sous odpowiadało 1 funtowi), zaś od 1467 r. Mikołaj otrzymywał wynagrodzenie co miesiąc ${ }^{24}$. Poza wykazami wypłacanego Mikołajowi wynagrodzenia nie dysponujemy innymi przekazami źródłowymi oświetlającymi pobyt naszego Mikołaja na dworze burgundzkim.

Od 1476 r. na dworze królów kastylijskich Izabeli I oraz Ferdynanda V pojawiał się lekarz określany mianem doctor Polonio ${ }^{25}$. Z dużą dozą prawdopodobieństwa możemy identyfikować go z naszym Mikołajem z Tuchowa, który posiadał także wykształcenie medyczne i od dłuższego czasu przebywał w tamtych rejonach Europy.

czas kontakty ze swoimi krakowskimi mistrzami, czego dowodzą losy wspomnianego wyżej rękopisu medycznego z jego kolofonem, który został nabyty za granicą do księgozbioru Andrzeja Grzymały (Catalogus codicum... qui in Bibliotheca Jagellonica Cracoviae asservantur, t. VI, s. 350-351).

${ }^{20} \mathrm{~J}$. T r é vé d y, Fous, folles et astrologues à la cour de Bretagne, Bulletin de la Société archéologique du Finistère 18, 1891, s. 13; J.P. B o u d e t, Les astrologues et le pouvoir sous le règne de Louis XI, w: Astrologie et politique entre Moyen Âge et Renaissance, Florence (w druku) - panu prof. J.P. Boudet dziękuję za udostępnienie mi tekstu artykułu.

${ }^{21}$ J. C h a b á s, Astronomy, s. 175; J. P. B o u d e t, Les astrologues; L. B a v e y e, Exercer la médecine en milieu princier au XVème sièe: l'exemple de la cour de Bourgogne, 1363-1482, praca doktorska obroniona w 2015 r. na Université Charles de Gaulle - Lille III), t. I, s. 31-33, 59-60, t. III, s. 456-458 (dostępne online: <https://tel.archives-ouvertes.fr/tel-01179585v2>; za zwrócenie mi uwagi na tę dysertację dziękuję panu prof. J.P. Boudet.

${ }^{22}$ Lille, Archives Départementales du Nord, B 2053, nr 63855; B 2071, nr 65277, 65278; B 2087, nr 66399, 66403; Comptes de l'argentier de Charles le Téméraire duc de Bourgogne, t. I: Année 1468. Le registre B 2068 des Archives Déartementales du Nord, wyd. A. Greve, É. Lebailly, red. W. Paravicini, Paris 2001, nr 497, 647, 742, 929, 1126, 1270, 1567, 1821, 2134.

${ }^{23}$ Lille, Archives Départementales du Nord, B 2087, nr 66399: „Je, Nicole de Poulaine, astronemien de Monseigneur le Duc de Bourg(ogne), confesse avoir receu de Nicolas de Gondeval, conseillier et argentier de mond(it) Seigneur, la somme de vint livres du pris de quarante gros monnoye de Flandres la livre, que icellui S(ieur) m'a de sa grace donnee pour une fois, pour moy entretenir honnesteme(n)t en son service, et mesmement pour convertir en mes neccessitez, de la quelle sonme de xx l(ivres) du pris et pour la cause que dessus je me tiens content et en quicte mond(it) S(eigneur), sond(it) argentier et tous autres à qui quictance en app(ar)tient; tesmoing le seing manuel de maistre Simon de le Kerrest, secretaire d'icellui S(eigneur) cy mis à ma requeste, le penultime jour de decembre l'an mil cccc soixante unze". Panu prof. Piotrowi Tylusowi dziękuję za odczyt powyższego dokumentu.

${ }^{24}$ L. B a v e y e, Exercer la médecine, t. I, s. 71, t. III, s. 458.

${ }^{25}$ Registro General del Sello, t. I, Valladolid 1950, nr 1329. 
Po dłuższym pobycie w Burgundii Mikołaj wrócił zatem na Półwysep Iberyjski, tym razem jednak jako lekarz ${ }^{26}$. W 1480 r. jest poświadczony jako „fisico examinador”, czyli medyk posiadający bardzo szerokie uprawnienia w zakresie przeprowadzania egzaminów potwierdzających umiejętności innych lekarzy, chirurgów i aptekarzy do wykonywania zawodu ${ }^{27}$. Wchodził wówczas w skład komisji zwanej Alcaldes examinadores mayores, która została powołana do życia przez króla Kastylii w $1477 \mathrm{r}^{28}$ Powodem powołania tej komisji było panujące w Kastylii olbrzymie rozprzężenie w zakresie rzemiosła medycznego, którym trudnili się ludzie bez wystarczającej do tego wiedzy. Dlatego też władca powołał to ciało w celu przeegzaminowania wszystkich medyków, chirurgów i aptekarzy ${ }^{29}$. Zakres kompetencji tej komisji był jednak znacznie szerszy. Król chciał, aby „alcaldes examinadores” mieli prawo pociągać lekarzy do odpowiedzialności osobistej i majątkowej za popełnione przestępstwa. W odniesieniu do aptekarzy członkowie komisji posiadali uprawnienia do kontrolowania aptek, a napotkane tam zepsute towary miały zostać spalone na głównym placu w danej miejscowości ${ }^{30}$.

Komisja liczyła 4 osoby i w momencie jej utworzenia weszli do niej: Juan Rodríguez de Toledo, Juan de Guadalupe, Lorenzo Bados oraz Juan Texen ${ }^{31}$. Tego ostatniego zastąpił w 1480 r. właśnie nasz Mikołaj. Już na początku tego roku Juan de Guadalupe, Lorenzo Bados oraz nasz Mikołaj upoważnili swojego kolegę, Juana Rodrígueza de Toledo, aby w ich imieniu wykonywał urząd alcalda examinadora W mieście Jerez ${ }^{32}$. Komisja alkaldów wzięła się energicznie do pracy, bo już 8 II 1480 r. znamy ich wniosek do sądu o aresztowanie Mathea Sebastiany, Greka przebywającego w Valladolid, i zabranie mu całego zapasu szczawiu i ziól, ponieważ jest on oszustem ${ }^{33}$. W Archiwum Generalnym w Simancas, gdzie znajdują się archiwalia królestwa Kastylii i Leonu, zachowały się księgi wydatków dworu, w tym także na lekarzy i chirurgów królewskich ${ }^{34}$. Wydatki na medyków wynotował niegdyś Juan

${ }^{26}$ J. L. Brou ard Uriarte, Medicos, cirujanos, barberos y algebristas castellanos del siglo XV, Cuadernos de Historia de la Medicina Española 11, 1972, s. 242, 252. Starszej literaturze Mikołaj nie był znany. Zob. N. Alons o Cortés, Dos medicos de los reyes catolicos, Hispania 45, 1951, s. 607-657. R.S. de S a n R o má n, Los médicos de la reina Isabel, Toletum. Boletín de la Real Academia de Bellas Artes y Ciencias Históricas de Toledo, ser. 2, 50, 2004, s. 129-144 (skupił się na jednym tylko medyku królowej, pochodzącym z Toledo Juanie Rodríguezie). Ostatnio natomiast J. D. G o n zále z A r c e, Los municipios contra el centralismo monárquico. La oposición concejil a los alcaldes mayores de las profesiones sanitarias en la Castilla del siglo XV, Studia Historica. Historia Medieval 32, 2014, s. 219, uważa (acz bez podania źródeł), że Mikołaj z Polski był już lekarzem króla Kastylii Henryka IV Bezsilnego.

${ }^{27}$ Registro General del Sello, t. II, Valladolid 1951, nr 2464.

${ }^{28}$ V. Gó m e z M a m pas o, Los Alcaldes examinadores mayores. Origen y competencia, Boletín de la Real Academia de 1 Historia 180, 1983, nr 3, s. 552-554; M.S. C a m p o s D í e z, El Real Tribunal del protomedicato castellano (siglos XIV-XIX), Cuenca 1999, s. 375.

${ }^{29} \mathrm{~V}$. Gó m e z M a m p a s o, Los Alcaldes, s. 559.

${ }^{30}$ Tamże, s. 553.

31 Szerzej nich: R.S. de S a n Ro mán, Los médicos, s. 129-144; A. de 1 a Torre, Un medico de los Reyes Católicos: Lorenzo Bados, Hispania 14, 1944, s. 66-72.

${ }^{32}$ Registro General del Sello, t. II, nr 3039.

33 Tamże, nr 2464.

${ }^{34}$ Archivio General de Simancas, Escribania Mayor de Rentas, Quitaciones de Corte. 
Manuel Jimenez Muñoz ${ }^{35}$. Wynika z nich, że znany nam już Juan Texen jako lekarz dworu królewskiego otrzymał wynagrodzenie wysokości 40000 maravedis (moneta używana przez kilka wieków w Hiszpanii) ${ }^{36}$ - acz nie wiemy, za jaki okres. Z kolei Juan Rodriguez de Toledo, także jeden $z$ alcaldes examinadores mayores, otrzymał za lata 1480-1494 w sumie 90000 maravedis ${ }^{37}$. Tyle samo wypłacono za ten sam okres służby Juanowi de Guadalupe ${ }^{38}$. Nie wiadomo, dlaczego wykazy nie obejmują ani Lorenzo Badosa, ani też naszego Mikołaja Polaka. Z pewnością otrzymywali oni wynagrodzenie za pełnienie zaszczytnej funkcji lekarza dworu, a potem członka wspomnianej komisji alcaldes examinadores mayores. Jak zresztą zaraz zobaczymy, Mikołaj dorobił się dosyć sporych oszczędności.

Z zachowanych źródeł wynika, że Mikołaj w nieznanym nam bliżej czasie ożenił się i miał syna Juana de Tejo, zamieszkałego w Medina del Campo. Syn ten 8 XI 1484 r. wytoczył proces klasztorowi w Mejorada (Olmedo), w którym jego ojciec, czyli nasz Mikołaj z Tuchowa, zdeponował pewną ilość złota ${ }^{39}$. Z zapiski wynika, że Mikołaj już wówczas nie żył ${ }^{40}$. Cenny depozyt dowodzi raczej sporych dochodów Mikołaja, o których jednak milczą zachowane wydatki dworskie. Z dokumentów wystawionych w 1493 r. dowiadujemy się, że żoną Mikołaja była Eleonora González. Domagała się ona wówczas wypłaty pewnej sumy, należnej za życia jej mężowi ${ }^{41}$.

Sumując powyższe rozważania, warto podkreślić, że w osobie Mikołaja z Tuchowa mamy do czynienia z polskim astronomem i lekarzem, który zrobił ciekawą karierę w Europie Zachodniej. Nie był wybitnym uczonym. Po studiach w Uniwersytecie Krakowskim i wszechnicy paryskiej (już podczas studiów dał próbkę swoich umiejętności, opracowując tablice astronomiczne dla Krakowa) został zatrudniony na uniwersytecie w Salamance i zajmował tam katedrę astronomii. Zapewne wtedy opracował tablice astronomiczne dla Salamanki. Nie znamy przyczyn, które skłoniły Mikołaja do opuszczenia (przed 1464) Salamanki. Po krótkim pobycie w Nantes osiadł jako astronom na dworze książąt burgundzkich (1464-1472). Swoje medyczne wykształcenie spożytkował Mikołaj po opuszczeniu dworu burgundzkiego, zatrudniając się jako lekarz (od 1476 r.) na dworze królów kastylijskich. Wchodził też w skład elitarnej komisji Alcaldes examinadores mayores. Jako dworski medyk ożenił się (miał syna Juana de Tejo), a także dorobił sporych oszczędności w złocie, które zdeponował w klasztorze w Mejorada (Olmedo).

${ }^{35}$ J.M. Jimenez Muñoz, Medicos y cirujanos en "Quitaciones de Corte" (14351715), Valladolid 1977.

36 Tamże, s. 98.

37 Tamże, s. 87-88.

38 Tamże, s. 54.

39 Registro General del Sello, t. III, Valladolid 1953, nr 3675. Zob. El monasterio de la Mejorada (Olmedo), catalogo documental 1368-1643, wyd. J. de la Fuente Crespo, Valladolid 2018, ale dokumenty klasztorne milczą jednak na temat złota zdeponowanego przez Mikołaja z Polski.

${ }^{40}$ M.V. A m a s un o Sárraga, The royal physicians as alcaldes and examinadores mayores: royal interference in medicine and law in Castile under Isabel and Ferdinand, w: Isabel la Católica, Queen of Castile. Critical essays, New York 2003, s. 125.

${ }^{41}$ Registro General del Sello, t. X, Valladolid 1967, nr 1898, 2623. 


\section{BIBLIOGRAFIA}

Alonso Cortés N., Dos medicos de los reyes catolicos, Hispania 45, 1951.

Amasuno Sárraga M.V., The royal physicians as alcaldes and examinadores mayores: royal interference in medicine and law in Castile under Isabel and Ferdinand, w: Isabel la Católica, Queen of Castile. Critical essays, New York 2003.

Baveye L., Exercer la médecine en milieu princier au Xvème sièe: l'exemple de la cour de Bourgogne, 1363-1482, praca doktorska obroniona w 2015 r. na Université Charles de Gaulle - Lille III, <https://tel.archives-ouvertes.fr/tel-01179585v2>.

Beaujouan G., L'astronomie dans la Péninsule Ibérique a la fin du Moyen Âge, Revista da Universidade de Coimbra 24, 1971.

Bednarski A., Materiały do dziejów medycyny polskiej w XIV i XV stuleciu, Kraków 1938.

Birkenmajer L. A., Mikołaj Wodka z Kwidzynia zwany Abstemius, lekarz i astronom polski XV-go stulecia, Roczniki Towarzystwa Naukowego w Toruniu 33, 1926.

Birkenmajer A., Andrzej Grzymała z Poznania, astronom i lekarz z XV wieku, Kwartalnik Historii Nauki i Techniki 3, 1958, nr 3.

Boudet J. P., Lire dans le ciel. La bibliothèque de Simon de Phares, strologue du XVe siècle, Bruxelles 1994.

Boudet J. P., Les astrologues et le pouvoir sous le règne de Louis XI, w: Astrologie et politique entre Moyen Âge et Renaissance, Florence (w druku).

Brouard Uriarte J. L., Medicos, cirujanos, barberos y algebristas castellanos del siglo XV, Cuadernos de Historia de la Medicina Española 11, 1972.

Campos Díez M. S., El Real Tribunal del protomedicato castellano (siglos XIV-XIX), Cuenca 1999.

Chabás J., Astronomy in Salamanca in the mid-fifteenth century: the tabulae resolutae, Journal for the History of Astronomy 29, 1998

Chabas J., The University of Salamanca and the Renaissance of Astronomy during the second half of the 15th Century, w: Universities and Science in the Early Modern Period, Dordrecht 2006.

Dobrzycki J., The 'Tabulae Resolutae', w: De astronomia Alphonsi regis, wyd. M. Comes, R. Puig, J. Samsó, Barcelona 1987; przedruk w: J. Dobrzycki, Selected Papers on Medieval and Renaissance Astronomy, Warsaw 2010.

Galoch Z., Prepozytura benedyktyńska w Tuchowie 1460-1821, Kraków 2004.

García Avilés A., Arte y astrología en Salamanca a finales del Siglo XV, Anuario del Departamento de Historia y Teoría del Arte 6, 1994.

Giedroyć F., Źródła biograficzno-bibliograficzne do dziejów medycyny w dawnej Polsce, Warszawa 1911.

Gieysztor A., Mistrzowie polscy Uniwersytetu Paryskiego w XIV i XV wieku, w: Wieki średnie. Medium aevum. Prace ofiarowane Tadeuszowi Manteufflowi w 60. rocznicę urodzin, Warszawa 1962.

Gómez Mampaso V., Los Alcaldes examinadores mayores. Origen y competencia, Boletín de la Real Academia de 1 Historia 180, 1983, nr 3.

González Arce J.D., Los municipios contra el centralismo monárquico. La oposición concejil a los alcaldes mayores de las profesiones sanitarias en la Castilla del siglo XV, Studia Historica. Historia Medieval 32, 2014.

Gronowski M.T., Zwyczajny klasztor, zwyczajni mnisi. Wspólnota tyniecka w średniowieczu, Kraków 2007.

Jimenez Muñoz J.M., Medicos y cirujanos en "Quitaciones de Corte” (1435-1715), Valladolid 1977.

Kiryk F., Miasta regionu tarnowskiego - Tarnów, Tuchów, Ciężkowice do końca XVI w., w: Tarnów. Dzieje miasta i regionu, red. F. Kiryk, Z. Ruta, Tarnów 1981.

Kiryk F., Urbanizacja Małopolski. Województwo sandomierskie XIII-XVI wiek, Kielce 1994. Krogulski F., Miasto Tuchów do roku 1657, Tuchów 2016 (Materiały do dziejów Tuchowa 7). 
Porres de Mateo B., Chabás J., Los cánones de las Tabulae Resolutae para Salamanca origen y transmisión, Cronos 1, 1998.

Rosińska G., Scientific writings and astronomical tables in Cracow. A census of manuscript sources (XIVth-XVIth centuries), Wrocław 1984 (Studia Copernicana, 22).

Rostafiński J., Medycyna na Uniwersytecie Jagiellońskim w XV wieku, Kraków 1900.

San Román R.S. de, Los médicos de la reina Isabel, Toletum. Boletín de la Real Academia de Bellas Artes y Ciencias Históricas de Toledo, ser. 2, 50, 2004.

Słownik staropolski, t. VIII, Wrocław 1981.

Torre A. de la, Un medico de los Reyes Católicos: Lorenzo Bados, Hispania 14, 1944.

Trévédy J., Fous, folles et astrologues à la cour de Bretagne, Bulletin de la société archéologique du Finistère 18, 1891.

Wickersheimer E., Commentaires la Faculté de médecine de l'Université de Paris (13951516), Paris 1915.

Wickersheimer E., Dictionnaire biographique des médecins en France au Moyen Âge, Paris 1936.

Zdanek M., Szkoły i studia dominikanów krakowskich w średniowieczu, Warszawa 2005.

\title{
Mikolaj of Tuchów. A forgotten astronomer and physician of the 15th century and his European peregrinations
}

\author{
Summary
}

Mikołaj of Tuchów was a Polish astronomer and physician, who made a career in Western Europe. After university studies in Cracow and Paris (during the Paris studies he proved his abilities by preparing astronomical tables for Cracow) he was employed at the university of Salamanca, where he took over the chair of astronomy. Probably it was then that he prepared astronomical tables for Salamanca. We do not know the reasons for his leaving Salamanca (before 1464). After a short stay in Nantes, he became the astronomer at the court of Dukes of Burgundy (1464-1472). A receipt of the salary paid to him has survived. After leaving the court of Burgundy, Mikołaj returned to his medical profession and was employed as a physician (from 1476 ) at the court of Kings of Castile. He was also a member of the prestigious commission Alcaldes examinadores mayores. As a court physician he got married (and had a son Juan de Tejo), and earned considerable wealth in gold, which he deposed at the monastery in Mejorada (Olmedo). He died before 1484. 